\title{
Inés Nercesian
}

\section{Presidentes empresarios y Estados capturados: América Latina en el siglo XXI.}

\author{
Teseo, Ciudad Autónoma de Buenos Aires, Argentina, \\ 2020, 246 pp.
}

Por Santiago Vanderstichel*

El libro Presidentes empresarios y Estados capturados constituye un aporte sustancial para comprender las dinámicas políticas en América Latina a partir del siglo XXI. A través del abordaje de este fenómeno relativamente nuevo, la autora logra dar cuenta de transformaciones históricas que se originaron en las estrategias de acumulación y la conformación de los grupos económicos en las décadas anteriores. Una síntesis pertinente podría surgir de la siguiente pregunta: ¿Qué transformaciones históricas condujeron a que los empresarios optaran por ejercer el poder de manera directa en el siglo XXI?

El fenómeno de captura estatal tiene una amplia literatura que analiza los mecanismos de lobby entre las décadas de 1970 y 1990, a partir de los cuales las corporaciones empresarias lograron vehiculizar sus intereses a través de las élites políticas. El rasgo más destacado de los nuevos presidentes empresarios, consiste en que deciden ocupar el Estado de manera directa, sin la mediación de los históricos elencos políticos. Si bien se difundió ampliamente el abordaje de este fenómeno a partir del concepto de puerta giratoria, la autora plantea las limitaciones para comprender estas experiencias desde su dimensión política. En contraposición, la investigación propone indagar los mecanismos

* Argentino. Licenciado en Sociología por la Universidad de Buenos Aires, Argentina. Maestrando en Estudios Sociales Latinoamericanos e investigador del Instituto de Estudios América Latina y el Caribe (Facultad de Ciencias Sociales-UBA). Buenos Aires, Argentina.vanderstichel@gmail.com 
de captura estatal en estrecha vinculación con los modelos de acumulación y los grupos económicos que ocupan el Estado.

En el apartado metodológico, cabe destacar la operacionalización de los conceptos empresario y Estado. El primero se refiere a individuos que ocupan cargos gerenciales, que usualmente poseen acciones de la empresa y tienden a compartir un compromiso y cosmovisión que trasciende su función económica; y el segundo, se refiere a la élite del Estado como un conjunto de instituciones relativamente autónomas, cuya relación con las clases económicamente dominantes debe ser estudiada en cada caso. Para lograr los objetivos propuestos, se combinaron estrategias metodológicas cuantitativas y cualitativas: por un lado, se trabajó con la base de datos del Observatorio Electoral de América Latina de la Facultad de Ciencias Sociales de la Universidad de Buenos Aires, UBA, y por otro, se realizaron entrevistas a ministros y ministras, funcionarios de primera línea, periodistas e investigadores, quienes dotan al libro de un cúmulo de información y riqueza de fuentes que fueron exhaustivamente analizadas a lo largo de los apartados.

En el proceso de análisis de datos y la construcción de la narrativa del libro se destaca el enfoque comparativo. La autora indagó profundamente su objeto a partir de la elección de ocho casos nacionales de presidentes empresarios, agrupados en función de las características sociohistóricas de cada país. Por un lado, Argentina, Brasil y México constituyen un grupo de países con economías más grandes, con mayor desarrollo económico y diversificación productiva, amplias capacidades estatales, con experiencias nacionales populares y sectores subalternos con capacidad de generar resistencias y modelos alternativos; y por otro lado, Chile, Colombia, El Salvador, Paraguay y Perú, que comparten un menor desarrollo económico y productivo, capacidades estatales más débiles y unas élites acostumbradas a hegemonizar el Estado. Este enfoque permite observar la tensión e interrelación permanente entre temporalidades nacionales y tendencias regionales, y manifiesta la dificultad de prever el curso de la política en la región.

En las diferentes secciones del libro se analizan las presidencias de Vicente Fox en México (2000-2006), Elías Antonio Saca González (2004-2009) en El Salvador, Sebastián Piñera (2010-2014 / 2018-actualidad) en Chile, Horacio Cartes (2013-2018) en Paraguay, Mauricio Macri (2015-2019) en Argentina, Pedro Pablo Kuczynski (2016-2018) 
en Perú, Álvaro Uribe Vélez (2002-2010) en Colombia; y Michel Temer (2016-2018) en Brasil, quien a pesar de pertenecer a la élite política brasileña, implementó un programa político que privilegió los intereses de las grandes corporaciones e inició el giro conservador del país.

La hipótesis subyacente a lo largo de la investigación consistió en que entre las décadas de 1970 y 1990 en América latina, las reformas neoliberales produjeron la transnacionalización y diversificación de actividades productivas y financieras de los grupos económicos. Este proceso regional generó un cambio en la composición de las clases dominantes, transformando a los viejos grupos, que surgieron al calor del modelo de industrialización por sustitución de importaciones; y emergiendo nuevos grupos, mayormente vinculados con actividades extractivas y financieras. A partir de siglo XXI, con la implosión de la vieja matriz del sistema partidario, que implicó la pérdida de legitimidad de elencos políticos y partidos tradicionales, tuvieron una gran preeminencia las investigaciones centradas en países donde surgieron experiencias posneoliberales, por fuera de las normas del Consenso de Washington. Sin embargo, en el mismo período sucedieron experiencias antagónicas en las que los grupos económicos decidieron ocupar el Estado para profundizar el orden neoliberal, o bien, frenar el desarrollo de experiencias progresistas. Desde la perspectiva de estos empresarios, en lugar de negociar con la élite estatal la definición de una política específica, se presentó la alternativa histórica de ejercer el poder estatal directamente, conjugando un sentido de época en el que había llegado el momento de ocupar el Estado.

En la primera sección, Los grupos económicos, cambios y continuidades, se analizan las transformaciones económicas que posibilitaron la trayectoria de estos empresarios. En esta línea, se caracterizan las diferentes etapas históricas que atravesaron las grupos económicos en la región: entre 1930 y 1973/1980 emergen los primeros conglomerados empresariales a partir del impulso del modelo de industrialización sustitutiva; entre las décadas de 1970 y 1990 se desarrollan las transformaciones neoliberales que posibilitaron la emergencia de nuevos grupos económicos y la transformación de los viejos, favorecidas por las políticas de liberalización y privatización; y a partir del siglo XXI se produce la coexistencia y disputa entre viejos y nuevos grupos económicos, en un capitalismo globalizado y financiado, que más que trans- 
formar las estructuras productivas como en la etapa anterior, buscó preservar las funciones de un Estado dependiente, la libre circulación de bienes y capitales.

En la siguiente sección, Los empresarios al poder, la autora describe las herramientas que utilizaron los empresarios para convertirse en políticos. A partir del análisis comparativo de las trayectorias políticas, pueden reconocerse tres estrategias diferentes: la utilización de viejas estructuras partidarias en Brasil, El salvador y Paraguay; la construcción de nuevas denominaciones para agrupamientos históricos en Chile y México; y la creación de nuevos partidos políticos en Argentina, Colombia y Perú. Como se mencionó anteriormente, este fenómeno no se explica únicamente por la crisis de los partidos políticos, sino que en cada experiencia nacional intervienen factores de larga duración como la fortaleza de los Estados y partidos, y elementos coyunturales como acuerdos políticos, conveniencias, marketing, entre otras. Estas trayectorias de ascenso a la presidencia son analizadas a lo largo del capítulo ponderando estas variables para cada caso.

Si bien el rasgo más notable de estas experiencias es que los presidentes son empresarios, en la sección Los empresarios y sus gabinetes se profundiza en el análisis de los gabinetes conformados por estos gobiernos. A pesar de que las estrategias de conformación de estos fueron diferentes en cada país, prácticamente todos incorporaron ministros y ministras provenientes del ámbito empresarial. Algunos como Mauricio Macri formaron un gabinete proveniente del mundo privado, otros como Vicente Fox mezclaron un gabinete de empresarios con perfiles más políticos para garantizar la transición y administración del Estado, y otros como Elías Saca González implementaron una estrategia clásica de reclutamiento de miembros del partido. A partir de estos ejemplos, se transluce un abanico de estrategias definidas por las dinámicas sociohistóricas de cada país.

De esta manera, el discurso generalizado de eficiencia y expertos ingresando a la política, fue acompañado por gabinetes de economistas, administradores de empresas e ingenieros. En la sección ¿Quién es quién? Perfiles de ministros y ministras se indagan sus trayectorias socioeducativas. A través de la elaboración de datos cuantitativos, se halló una tendencia hacia altos grados de calificación en estudios de posgrado, mayoritariamente en áreas de economía, administración de 
empresas y finanzas, en universidades estadounidenses. En un contexto de globalización, la pertenencia a redes internacionales, la formación en ideas cosmopolitas y patrones universales, constituyen un criterio de selección de los gabinetes y un sesgo en la orientación y visión de las políticas de gobierno. Además, se comparan las trayectorias laborales para distinguir entre cuadros políticos, tecnócratas, y perfiles híbridos. Por último, se destaca la baja participación de mujeres en estos gabinetes, que vislumbra la dificultad de este género para alcanzar mayores puestos de jerarquía.

Finalmente, en la sección La reinvención. Escenarios híbridos y Estados capturados la autora realiza un balance de los caminos trazados por estas experiencias cuando dejaron el poder. Desde esta mirada, en todos los casos analizados se identifica un denominador común: la representación política de sectores económicamente dominantes en disputa; además, en todos los países con experiencias previas progresistas se produjo un cambio sustantivo en la política económica y, en el resto de los países se profundizó el sesgo económico neoliberal preexistente. Sin embargo, el desenlace de estas experiencias fue diverso, y dependió de las condiciones históricas de cada país. Macri perdió las elecciones tras los fracasos en materia económica y el intento de repolitizar su imagen; Temer finalizó su mandato con niveles muy bajos de aprobación, aunque habilitó la senda para la elección de Bolsonaro; la legislación de México impidió la reelección de Fox, quien no pudo imponer a su candidato en el partido; Piñera perdió la reelección, pero volvió a triunfar luego del gobierno de Bachelet; Uribe construyó una fuerza política propia que gravita la política colombiana; en El Salvador no hay reelección inmediata y el candidato de Saca fue derrotado en elecciones; Cartés tampoco pudo imponer a su candidato en las elecciones internas del Partido Colorado; y en Perú Kuczynski renunció tras recibir denuncias de corrupción y enfrentar la oposición fujimorista en el Congreso.

En el escenario de crisis económica desencadenado por la pandemia del COVID-19 se profundizó la concentración económica y la persistencia de estos grupos para ocupar áreas centrales de la economía y el Estado. El libro resulta un aporte valioso para comprender estas dinámicas políticas recientes, desde la comparación de casos, la interrelación permanente entre procesos regionales y particularidades 
nacionales, la riqueza de fuentes, la elaboración de tipologías, cuadros y el análisis exhaustivo de los datos; producen una investigación integral, que aporta una mirada renovada respecto de un fenómeno que no fue suficientemente estudiado. Desde la perspectiva propuesta por la autora resulta comprensible la vocación de estos empresarios por ocupar el Estado y abre interrogantes en torno a los procesos políticos recientes: ¿Qué transformaciones históricas produjeron las políticas económicas desplegadas durante la pandemia? ¿Qué cambios se generaron en la composición de los grupos económicos y las clases económicamente dominantes? ¿Qué mecanismos políticos utilizaron para vehiculizar sus intereses en este contexto? ¿Cuál es el legado de estos presidentes empresarios en las dinámicas políticas regionales? Entre otras preguntas y elaboraciones que podrían surgir de lecturas futuras.

\section{Referencias}

Nercesian, I. (2020). Presidentes empresarios y Estados capturados: América Latina en el siglo XXI. Teseo. 